\title{
La explotación didáctica de la novela gráfica en la clase de ELE: una propuesta a partir de La casa de Paco Roca
}

\author{
CRISTINA Villalba IBÁÑEZ \\ Universitat de València / Universitat Jaume I \\ cristina.villalba@uv.es
}

\begin{abstract}
Resumen: El objetivo de este trabajo es compartir una experiencia diseñada a partir de la explotación didáctica de la novela gráfica La casa (2015) de Paco Roca con un grupo de estudiantes de nivel B2. Tradicionalmente, el cómic se ha trabajado en el aula de ELE a partir de tiras cómicas o de secuencias breves. Sin embargo, en esta propuesta se reivindican las ventajas didácticas de este medio, sobre todo a partir de obras más extensas, para desarrollar el gusto estético y literario, favorecer la adquisición de estrategias de interpretación, elaborar inferencias y trabajar aspectos culturales y afectivos. Para lograrlo, a lo largo de la secuencia se presentan algunas de las obras más importantes del cómic en España, se ofrecen claves de lectura para sensibilizar al alumnado con las convenciones de este medio y se favorece la reflexión sobre la obra en relación con la experiencia personal.
\end{abstract}

Palabras clave: cómic, novela gráfica, comprensión lectora, ELE

\section{Abstract:}

The goal of this work is to share an experience based on the didactic exploitation of the graphic novel La casa (2015) by Paco Roca with a group of students with B2 level. Traditionally, the comic has been used in the SFL classroom through comic strips or short sequences. However, in this proposal we claim the didactic advantages of this medium, especially in more extensive works, to develop the aesthetic and literary taste, favor the acquisition of interpretation strategies, draw inferences and work on cultural and affective aspects. To achieve this through the sequence, we present some of the most important comic books in Spain, we offer reading keys to sensitize students to the conventions of this medium and we encourage to stablish a relation between the reading and the personal experience.

Keywords: comic, graphic novel, Reading comprehension, SFL

\section{Introducción}

El empleo de tebeos en el aula de ELE no es algo propiamente novedoso. La aparición de personajes clásicos de la cultura hispánica como Mafalda o Mortadelo y Filemón lleva utilizándose como recurso motivador para trabajar la comprensión lectora de una manera amena y divertida desde hace tiempo. Ahora bien, en los últimos años la industria asociada al sector del cómic ha evolucionado hacia nuevos formatos especialmente interesantes para trabajar en clase. El medio del cómic ya no sirve únicamente como vehículo de expresión para historias humorísticas breves, sino que también tienen cabida otros enfoques y temas donde la risa no tiene por qué ser la protagonista. 
En español, tenemos varias maneras de designar a las historias contadas de manera gráfica (tebeo, historieta, cómic y, más recientemente, novela gráfica). La primera definición que nos ofrece el Diccionario de la lengua española para la definición de tebeo es 'publicación infantil o juvenil cuyo asunto se desarrolla en series de dibujos'. Esta definición pervive en la mente de muchos hablantes (docentes y aprendices de español), y conlleva una visión reduccionista de las posibilidades que ofrece este medio. Algo similar sucede con la denominación «cómic» e «historieta», que se asocia a las lecturas de los más jóvenes.

En relación con esto, una definición más adecuada de cómic, tebeo o historieta sería «ilustraciones yuxtapuestas y otras imágenes en secuencia deliberada, con el propósito de transmitir información y obtener una respuesta estética en el lector» (McCloud, 1995, p. 9). De ello se desprende que el cómic es un soporte, un formato flexible en el que tienen cabida distintos tipos de historias.

El término «novela gráfica» es el más reciente. Acuñado por el crítico R. Kyle (1964), popularizado por autores como W. Eisner y ampliamente utilizado en la mercadotecnia, la etiqueta de «novela gráfica» se concibió con el objetivo de reivindicar las características del cómic o el tebeo para tratar historias y abordar temas que no necesariamente se vinculasen a lo cómico o infantil. En este trabajo utilizaremos los términos cómic, tebeo o historieta para referirnos a un formato concreto para contar historias (sin definir, a priori, el destinatario) y reservaremos novela gráfica para aquellas obras que utilizan el dibujo y la palabra para abordar historias extensas que, generalmente, tienen carácter autoconclusivo.

\section{Explotación didáctica del cómic}

El uso que generalmente encontramos en las propuestas didácticas que utilizan tebeos en el aula de ELE es a partir de viñetas aisladas o de tiras cortas, generalmente de carácter cómico. Algunos ejemplos de actividades clásicas que se pueden trabajar a partir de este input son:

1. Transcribir el contenido en estilo indirecto

2. Trabajar la entonación a partir de la lectura de los bocadillos

3. Ocultar una viñeta de una secuencia y pedir que la describan teniendo en cuenta el resto de viñetas.

4. Usar cómics mudos y pedir a los estudiantes que imaginen los pensamientos de los personajes.

5. Intentar explicar lo sucedido desde el punto de vista de cada personaje.

6. Hacer una grabación de las viñetas.

7. Dejar los bocadillos en blanco, dar el contenido de los bocadillos de manera desordenada y pedir que se ordenen de forma secuencial

8. Dejar los bocadillos en blanco y pedir que creen un diálogo

(Brown, 1977: 22)

Las actividades que aparecen en el listado muestran que el uso de los cómics en el aula de ELE se ha centrado, fundamentalmente, en la explotación lingüística del material. Sin duda, el carácter dialogal de muchas historietas permite presentar intercambios más o menos realistas donde se manifiestan con naturalidad distintos registros de la lengua. Por ello, este enfoque es útil, pero reduccionista, ya que descuida otros aspectos que resultan igualmente interesantes en el aula de ELE. Este es el caso del tratamiento de la gestualidad o de aspectos culturales, como reivindican otros autores en sus trabajos (Brines Gandía, 2012; Escudero Medina, 2006; Espinosa-Guerri, 2018). 
Un cómic, al igual que un poema o una película, es una producción cultural que responde (entre otras motivaciones) a una voluntad estética. No en vano, los tebeos son también conocidos como el noveno arte. El empleo de los cómics en el aula de ELE permite tratar el componente cultural de una manera orgánica, especialmente si son de corte histórico o costumbrista. Son materiales reales elaborados en el seno de una sociedad que representan las inquietudes e intereses de quien escribe y de sus potenciales lectores. El paisaje, los edificios, la ropa, la manera en que unos personajes se relacionan con otros... Todo ofrece información acerca de la cultura en la que se enmarca la obra. En este sentido, los cómics abren una ventana a ese mundo del mismo modo que lo haría una película, con la diferencia de que el formato permite un acercamiento más sosegado y con menos frustración (pues se dispone de más tiempo para procesar la información).

El cómic también se ha empleado como actividad inicial motivadora para el desarrollo de otras actividades o como paso previo a otro tipo de lecturas de más envergadura: «there is evidence suggesting that comic book reading can be a conduit to 'heavier' reading» (Krashen, 2005, p. 2). Posicionamientos como el de Krashen, que caracterizan a los cómics como lecturas ligeras y banales, contribuyen a tener una percepción limitada de sus posibilidades de explotación en el aula. Evidentemente, leer cómics puede ser una estrategia fantástica para el fomento lector. No obstante, entender la lectura de historietas como un ejercicio de introducción a otras actividades o un acercamiento a la literatura «de verdad» puede excluir a este medio de lo que entendemos como cultura y hacernos olvidar que es un medio válido por sí mismo (Del Rey Cabero, 2013, pp. 182-183), como demuestra el reconocimiento de la crítica de novelas gráficas como $A$ Contract with God and Other Tenement Stories (Eisner, 1978), El arte de volar (Altrarriba y Kim, 2016).

Otro aspecto que se debe tener en cuenta es que el desarrollo de la comprensión lectora en L2 es un proceso distinto a la de la L1. Las principales diferencias, de acuerdo con Koda (1994) residen en tres puntos. En primer lugar, la experiencia lectora en la L1 es más dilatada (especialmente en el caso de los adultos) que en el caso de la L2. En consecuencia, los aprendientes disponen en su lengua materna de un desarrollo mayor de estrategias metacognitivas que deben adaptar o reinventar cuando se enfrentan a la lectura en L2. En segundo lugar, la lectura en el marco de la L2 es un proceso cognitivo más complejo. A diferencia de lo que sucede cuando los aprendientes se enfrentan a textos en L1, la comprensión lectora en L2 es un proceso donde ambas lenguas interactúan (Koda, 2007), por lo que el acompañamiento del docente y el diseño de actividades que guíen el proceso de lectura es fundamental. Por último, los conocimientos lingüísticos que muestra el aprendiente en la L1 son considerablemente superiores a los de la L2, por lo que el desarrollo de esta destreza puede generar frustración.

Dentro de los materiales destinados al desarrollo de la comprensión lectora, se ha destacado el papel de los tebeos para aliviar la ansiedad que produce enfrentarse a las lecturas en lenguas extranjeras. Lo atractivo del formato, unido a la posibilidad de aprovechar dos fuentes de información (la lingüística y la visual), aumentan la comprensión del alumno, sobre todo en los niveles iniciales (Liu, 2004), y tienen un efecto positivo en la realización de la tarea con éxito y en su propio aprendizaje (Consejo de Europa, 2001, pp. 159-160). En relación con este punto, podría parecer que trabajar la comprensión lectora a través de los cómics es adecuado solo para los primeros niveles del proceso de adquisición de una lengua, pues las limitaciones en la competencia lingüística se suplen con las imágenes. Sin embargo, es un material tan versátil que, en función de la obra y los objetivos que se pretendan trabajar, se puede utilizar en todas las etapas (Sáez Rivera, 2011). 
El uso del cómic facilita, además, el desarrollo de varias capacidades asociadas a la comprensión lectora. En la misma línea que Acquaroni (2000) y Issa (2018), entendemos que esta es una destreza activa, pues entraña un proceso complejo en el que interactúan factores de distinta naturaleza, como pueden ser culturales, lingüísticos, cognitivos y estratégicos, entre otros. La lectura de textos, especialmente si es continuada, estimula la capacidad de interpretación, que resulta fundamental para mejorar la competencia comunicativa del aprendiz. En el caso concreto de los cómics, cabe destacar que el ritmo de lectura sincopado se relaciona directamente con esta capacidad, puesto que se estructuran a partir de momentos discontinuos. Esto facilita que el lector elabore estrategias para conectar esas partes, para rellenar los vacíos de información gracias a su conocimiento del mundo y a su capacidad de conectar informaciones McCloud (1995, p.67).

En definitiva, los tebeos son una valiosa herramienta para propiciar el desarrollo de estrategias lectoras y de comunicación. Estas mejoran los procesos de interpretación causados por restricciones lingüísticas o ausencia de conocimientos, en la línea de lo propuesto por el MCER (Consejo de Europa, 2001, p. 74). Además, permiten abordar contenidos culturales y lingüísticos de una forma amena y motivadora, hecho que redunda positivamente en el progreso del estudiante.

\section{Propuesta de lectura}

La propuesta didáctica que se presenta a continuación ha sido diseñada para trabajar con un grupo de diez estudiantes universitarios estadounidenses que están realizando un curso intensivo de español durante cuatro semanas en España. Aunque el nivel de lengua es B2, el grupo es heterogéneo. Hay alumnos que tienen el español como lengua de herencia y muestran grandes aptitudes en la expresión oral, pero se sienten inseguros en la comprensión y expresión escrita. Del mismo modo, hay estudiantes que han cursado estudios de español en su universidad o en el instituto con diferentes niveles de competencia en las distintas destrezas.

Cada dos semanas, los estudiantes deben realizar una tarea final en la que exponen algún contenido relacionado con lo visto durante las sesiones de clase y relacionarlo con alguna obra cultural (como una película o una novela). Coincidiendo con el regreso de los estudiantes a sus hogares, la última tarea consiste en explicar oralmente la historia de la casa familiar a partir de la novela gráfica de Paco Roca La casa (2015). Para poder preparar la presentación de esta segunda tarea final del curso, durante las clases se trabajaron distintos contenidos gramaticales (contraste de los tiempos de pasado, estructuras condicionales), funcionales (hacer hipótesis, narrar anécdotas y recuerdos, expresar convencimiento y falta de certeza) y léxicos (objetos domésticos, arquitectura, literatura y tiempo libre). En las siguientes líneas se presenta un resumen de las actividades que se realizaron con los estudiantes. En primer lugar, se presentan las dos sesiones dedicadas a la prelectura, que tuvieron carácter presencial; seguidamente, se presentan las actividades desarrolladas durante la fase de lectura, que los estudiantes realizaron de manera autónoma a través de TIC; finalmente, se muestran los contenidos de las dos sesiones dedicadas a las actividades tras la lectura, que tienen un carácter presencial. 


\subsection{Actividades de prelectura}

Es importante que se presente de una manera contextualizada la obra con la que se va a trabajar, que despierte interés y curiosidad en los lectores y que el alumnado entienda su relación con lo que se le va a pedir en la tarea final. Por ello, las actividades de prelectura se desarrollaron en dos sesiones de hora y media cada una.

La primera sesión consistió en una presentación de la novela gráfica en España. En primer lugar, se plantearon algunas afirmaciones relacionadas con la percepción que suele tener el alumnado sobre el cómic. Esta actividad nos ayudó a reflexionar con los alumnos sobre la entidad del cómic como producto cultural y cuestionar algunos prejuicios relacionados con este medio.

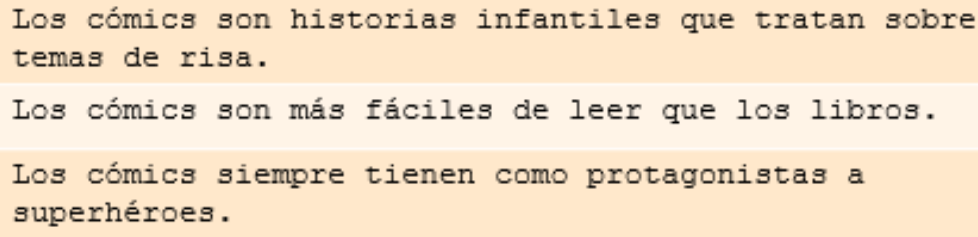

Imagen 1. Encuesta sobre la percepción del alumnado respecto al cómic.

A continuación, aquellos alumnos que se consideraban lectores de cómics o que habían leído cómics durante su infancia contaron su experiencia. Algunos habían leído cómic americano o japonés, pero ninguno había leído cómics en español ni conocía obras españolas. Teniendo en cuenta esta posible carencia, se preparó otra actividad en la que aparecían algunas de las novelas gráficas más populares en España que, además, se han escrito originalmente en español. Los estudiantes tenían que imaginar la temática de estas obras a partir de la interpretación de los elementos gráficos y su relación con el título.

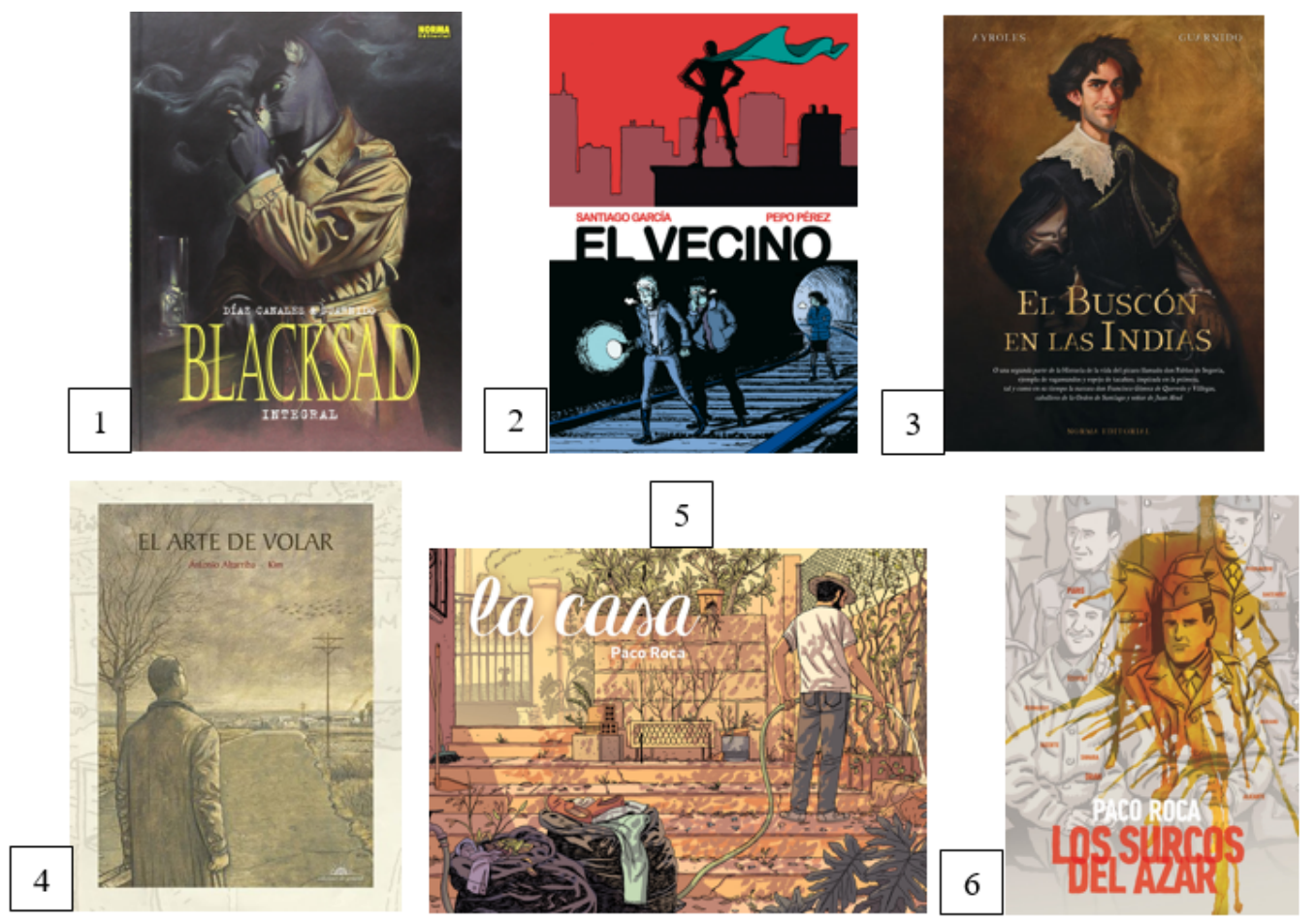

Imagen 2. Selección de portadas de cómics españoles. 
del texto supone educar la mirada y fomentar el desarrollo de destrezas cognitivas que atiendan a esta doble naturaleza.

Para favorecer su capacidad inductiva en relación con este medio, se tomaron las primeras páginas de La casa (imagen 5) donde no aparece ningún elemento textual. A continuación, se plantearon preguntas destinadas a reflexionar sobre aquello que está codificando el autor a través de las distintas secuencias, los elementos que aparecen en ellas, las onomatopeyas o el tratamiento del color.

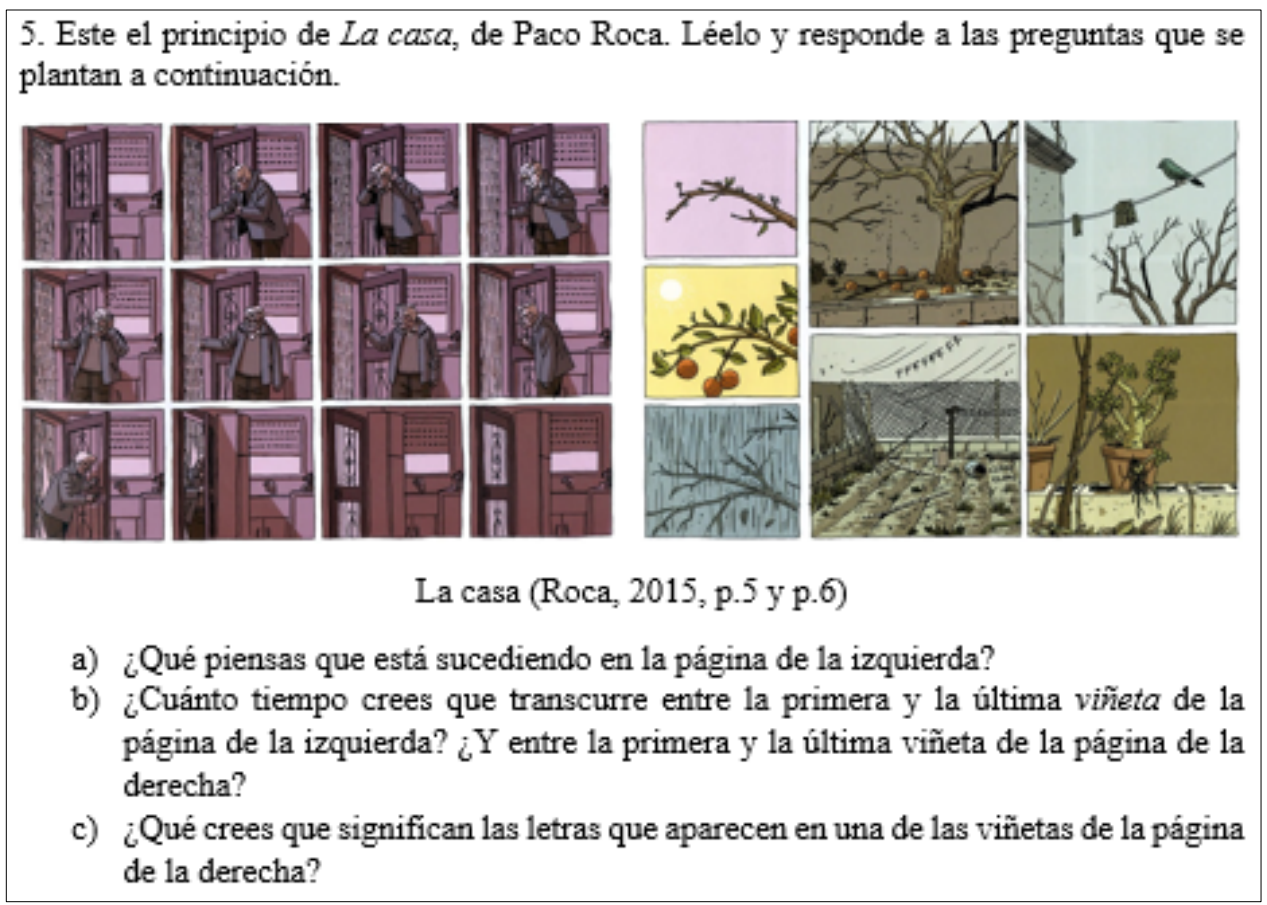

Imagen 5. Muestra de actividad para educar la mirada del lector de cómic

\subsection{Actividades durante la lectura}

Un buen trabajo de comprensión lectora necesita un seguimiento de la actividad, especialmente si la lectura, como fue nuestro caso, se hace fuera del aula. Como la obra tiene una estructura fácilmente divisible en tres partes (una por cada hijo), se pidió a los estudiantes que desarrollaran un diario de lectura a través de tres formularios de Google. Los alumnos podían ir completando los formularios a medida que fueran leyendo la obra, pero no podían rebasar la fecha límite en la que se iniciarían las actividades tras la lectura. 


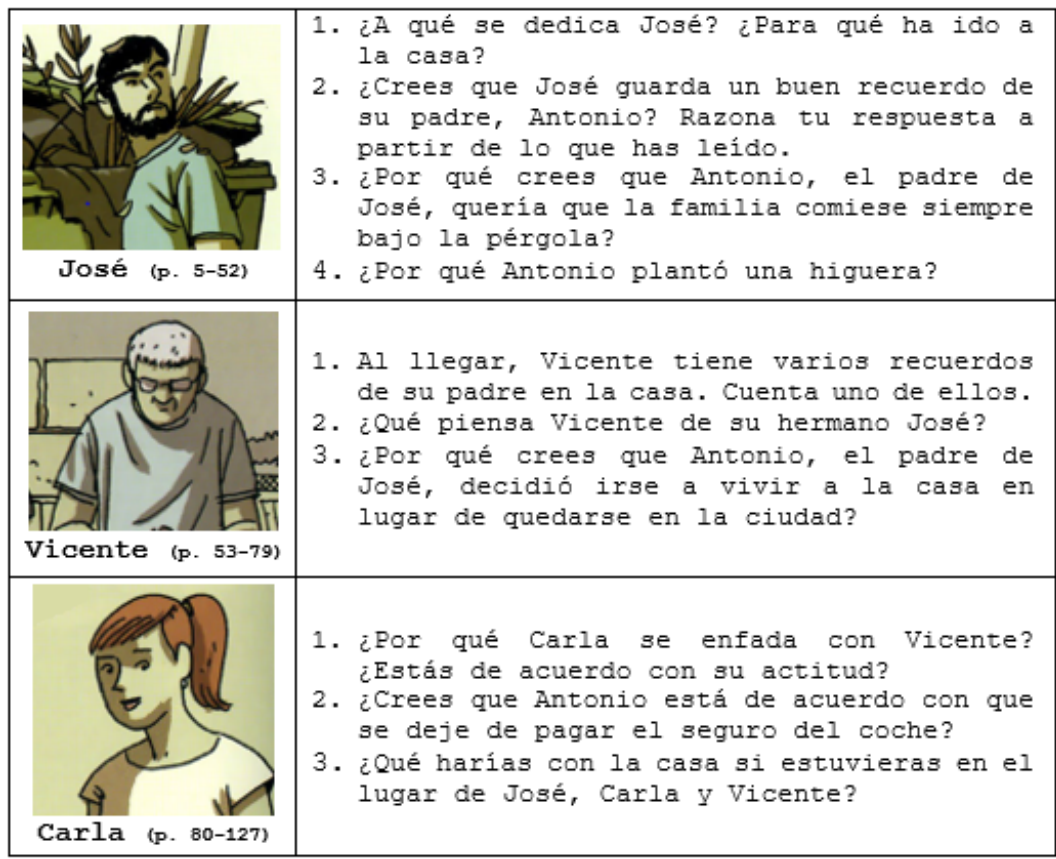

Imagen 6. Cuestionario de lectura

En este formulario, se pedía información declarativa para comprobar que los aprendientes estaban realizando la actividad sin grandes dificultades. Nos referimos a preguntas como ¿A qué se dedica José? (ver imagen 6). A su vez, se instaba a los aprendices a que interiorizaran la lectura y se atrevieran a plantearan hipótesis sobre lo que pensaban que les estaba sucediendo a los personajes, la relación que tenían entre ellos o la manera en que se podrían resolver los acontecimientos.

Nuestros objetivos con este diario de lectura se pueden resumir en tres puntos. En primer lugar, el diario de lectura a través de los formularios es un instrumento que ayuda a evitar la lectura precipitada de la novela gráfica la noche anterior. En segundo lugar, esta lectura pautada permite crear un espacio de reflexión personal en el que el alumnado pueda organizar sus ideas por escrito, focalice su mirada en puntos de interés dentro de la obra y haga una interpretación propia del texto. Por último, el diario de lectura propicia una actitud más participativa a la hora de discutir la obra, ya que el alumnado siente que tiene argumentos e ideas los suficientemente maduras para compartirlas con el grupo.

\subsection{Actividades tras la lectura}

Una vez acabada la lectura, realizamos durante la sesión 3 un pequeño club de lectura en el que se pidió a los alumnos que debatieran sus opiniones sobre La casa. Para facilitar el debate, se plantearon algunas preguntas (ver imagen 7), si bien es cierto que los estudiantes, que ya habían reflexionado sobre la obra a partir del diario de lectura, plantearon sus propias inquietudes sobre la obra y fueron capaces de razonar de forma elaborada sus hipótesis. 


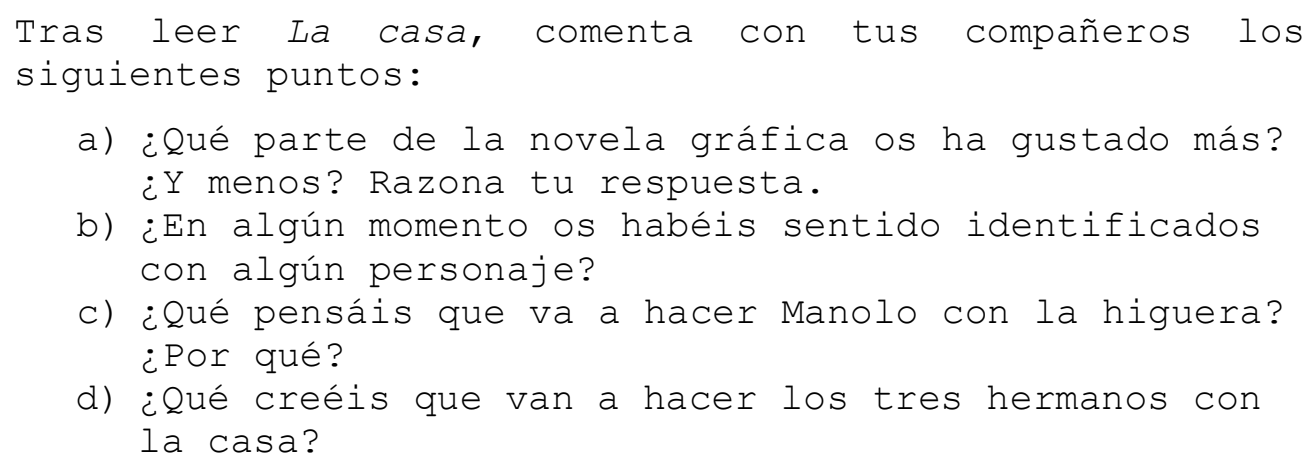

Imagen 7. Preguntas del club de lectura

La última pregunta fue la que generó más debate, pues en la obra los hermanos no parecen tomar una decisión clara sobre el destino de la casa. Este final abierto y su discusión sirvieron, a su vez, de actividad motivadora para la lectura de un texto breve en el que Paco Roca explica qué decisión tomaron sus hermanos y él mismo a propósito de la casa familiar. Tanto el debate como la lectura con la decisión final ayudaron a los alumnos a contextualizar aún más la obra y ubicarla en un momento histórico concreto.

Por último, en la sesión 4 (la última del curso antes de su regreso), los alumnos tenían que hacer una presentación de seis minutos en la que tenían que compartir la historia de la casa familiar, explicar si tenían algún rincón favorito y contar algún recuerdo o anécdota. Si lo deseaban, podían apoyar su presentación con una presentación de diapositivas con imágenes.

Esta actividad se concibió para que los alumnos se adueñaran del texto y lo interiorizaran con el objetivo de dar lugar, posteriormente, a una creación personal. El alumnado se implicó especialmente con esta actividad y, en algunos casos, los estudiantes llegaron a establecer relaciones entre algunos momentos de la obra y su propia experiencia personal. A pesar de tratarse de una actividad de la clase de ELE, muchos llegaron a conectar con esta actividad desde un punto de vista afectivo, lo que incrementó su disposición a comunicarse con el resto de sus compañeros en español. Asimismo, algunos estudiantes manifestaron su interés por conocer más novelas gráficas en español para leer por su cuenta y desarrollar esta destreza de manera autónoma.

\section{Conclusión}

En esta propuesta se muestra un ejemplo de explotación de una novela gráfica en la clase de ELE de forma contextualizada. En ella se trabajan todas las destrezas de manera integrada, si bien es cierto que se presta especial atención a la comprensión lectora no solo como una destreza lingüística, sino como un elemento motivador que puede convertirse en fuente de disfrute. En este sentido, la propuesta que se ha hecho a partir de La casa refuerza la idea de que el cómic puede ser una herramienta atractiva para llevar al aula por varios motivos.

En primer lugar, se trata de un medio que resulta atractivo y accesible por la combinación que se hace entre imagen y texto. En muchos casos, las imágenes pueden ayudar a comprender mejor el texto o explicar conceptos complejos para los que el alumno quizás no tiene suficiente competencia lingüística. Por ello, desde un punto de vista didáctico, resulta imprescindible ofrecer claves de lectura para interpretar correctamente convenciones propias de este soporte y dar a conocer las particularidades del dibujo o del 
color de la obra con la que se está trabajando. En nuestra experiencia, el seguimiento que se hizo de los diarios de lectura nos permitió comprobar que el nivel de comprensión de la obra fue alto y razonablemente homogéneo dentro del grupo, pese a los distintos grados de competencia de los estudiantes.

Además, el ritmo de lectura sincopado de los tebeos los hace especialmente útiles para desarrollar procesos cognitivos como la interpretación o la elaboración de inferencias, que son vitales para mejorar la competencia comunicativa del aprendiz. No solo eso, la articulación del relato a partir del diálogo también favorece el desarrollo de esta capacidad, pues tiene que relacionar lo dicho con lo implícito.

Por último, el cómic es un producto cultural -como una canción, una novela o una película- a partir del cual el estudiante puede comprender mejor la sociedad de la lengua que desea aprender. Los temas que se tratan, las inquietudes que manifiestan los personajes, los escenarios o las relaciones que se establecen entre los personajes ofrecen un input valiosísimo que se combina con el material lingüístico para crear una experiencia única de lectura.

\section{Bibliografía}

ACQUARONI, R. (2000). Del texto apropiado a la apropiación del texto: El tratamiento de la comprensión lectora en la enseñanza-aprendizaje de E/LE según las principales orientaciones metodológicas. Carabela, 48, pp. 45-63.

AltrarribA, A., \& KIM. (2016). El arte de volar. Norma.

BRINES GANDÍA, J. (2012). La rentabilidad del cómic en la enseñanza de la cultura en E/LE. Foro de profesores de E/LE, 8, Article 0. https://doi.org/10.7203/foroele.0.6604

Brown, J. W. (1977). Comics in the Foreign Language Classroom: Pedagogical Perspectives. Foreign Language Annals; New York, 10(1). https://search.proquest.com/docview/1311685540/citation/54421F073EA44192PQ/1

CONSEJO DE EUROPA. (2001). Marco común europeo de referencia para las lenguas: Aprendizaje, enseñanza, evaluación. MECD y Anaya. http://cvc.cervantes.es/ensenanza/biblioteca_ele/marco/cvc_mer.pdf

Del Rey CABERO, E. (2013). El cómic como material en el aula de E/LE: Justificación de su uso y recomendaciones para una correcta explotación. Revista española de lingüistica aplicada, 26, pp. 177-196.

EISNER, W. (1978). A Contract with God and Other Tenement Stories. Baronet Books.

ESCUDERO MEDINA, C. (2006). La enseñanza por tareas: Una expectativa para la integración del cómic en la clase de ELE. Boletín de la Asociación para la Enseñanza del Español como Lengua Extranjera, 35, pp. 31-36.

ESPINOSA-GUERRI, G. (2018). Viñetas de vida: Una propuesta de Aprendizaje-Servicio a través del cómic. Foro de profesores de E/LE, 14, Article 14. https://doi.org/10.7203/foroele.14.13336

ISSA, S. (2018). Comics in the English classroom: A guide to teaching comics across English studies. Journal of Graphic Novels and Comics, 9(4), pp. 310-328. https://doi.org/10.1080/21504857.2017.1355822 
KoDA, K. (1994). Second language reading research: Problems and possibilities. Applied Psycholinguistics, 15(1), pp. 1-28. https://doi.org/10.1017/S0142716400006950

KoDA, K. (2007). Reading and Language Learning: Crosslinguistic Constraints on Second Language Reading Development. Language Learning, 57(s1), pp. 1-44. https://doi.org/10.1111/0023-8333.101997010-i1

KRASHEN, S. (2005). The «Decline» of Reading in America, Poverty and Access to Books, and the use of Comics in Encouraging Reading. Teachers College Record. http://www.sdkrashen.com/content/articles/decline_of_reading.pdf

KyLE, R. (1964). The future of «comics». Richard Kyle's Wonderworld 2, pp. 3-4.

LIU, J. (2004). Effects of comic strips on: L2 learners' reading comprehension. TESOL Quarterly, 38(2), pp. 225-243. https://doi.org/10.2307/3588379

McCloud, S. (1995). Cómo se hace un cómic. El arte invisible. Ediciones B.

RocA, P. (2015). La casa. Astiberri.

SÁEz RIVERA, D. M. (2011). Tendencias, posibilidades y experiencias en E/LE del cómic como texto multimodal. En S. De Santiago Guervós, M. Seseña Gómez, J. J. Sánchez Iglesias, \& H. Bongaerts (Eds.), Del texto a la lengua: La aplicación de los textos a la enseñanza-aprendizaje del español L2-LE, Vol. 2 (pp. 769-780). ASELE. http://www.cervantesvirtual.com/nd/ark:/59851/bmc0z950

Materiales didácticos disponibles en:

https://www.academia.edu/42951651/Explotaci\%C3\%B3n_did\%C3\%A1ctica_de_la_novela_gr $\%$ C3\%A1fica_La_casa_de_Paco_Roca_en_el_aula_de_ELE_B2 